\title{
Use of Microblogging, Social Networking, and Short Messages in E-learning for Information Culture Building
}

\author{
https://doi.org/10.3991/ijet.v16i14.22391 \\ Marina Kolmykova $(\bowtie)$ \\ Orenburg State University, Orenburg, Russian Federation \\ marikolmykova@rambler.ru \\ Nadezhda Gavrilovskaya, Mariya Barsukova \\ Russian State Agrarian University - Moscow Timiryazev \\ Agricultural Academy, Moscow, Russian Federation \\ Daria Kozlovskaya \\ Russian State Social University, Moscow, Russian Federation
}

\begin{abstract}
This work examines the effect of microblogging, social networking, and short messaging in e-learning on the process of information culture formation. The current study develops and tests an experimental Moodle-based course in management psychology for master-level students, which implies the use of Instagram. Participants were recruited from the Higher School of Economics and Business (Al-Farabi Kazakh National University) together with the Institute of Economics and Management in Agribusiness (Russian State Agrarian University - Timiryazev Moscow Agricultural Academy (RSAU - MTAA)). Students were asked to briefly express their thoughts, attitudes, and views toward the given topic on Instagram by creating blog posts and leave motivational and constructive comments under the blogs of other group members. Online surveys were used, which investigated the effect of innovative teaching (use of microblogs) on learning and learners' emotional responses. The study discusses the use of microblogging on Instagram as an educational tool. The majority of respondents reported a positive effect of microblogs. According to learners, the use of Instagram gave the learning journey a makeover, making it relevant, effortless, and consistent. Using microblogs created favourable conditions for collaborative learning, creative self-expression, and systematization of knowledge and experiences. Students reported that doing microblogs was entertaining, motivating, and beneficial to their critical thinking, writing skills, and communication competency.
\end{abstract}

Keywords-Microblog; information culture; information society; social network; social relationship 


\section{Introduction}

Digitalization is bound to affect the formation of social capital. Social relations are thus expected to acquire new features. Internet technology allows people to communicate, work, and learn in virtual spaces. With its help, individuals were able to maintain social connections during the global pandemic. As the Internet penetrates our lives, it causes the social reality to transform. Consequently, a new form of social relations emerges. This new form of Internet-based community has its values and rules of behaviour, whereby makes it a source of virtual culture.

Culture has two main functions, namely integration and adaptation [1]. From this perspective, information culture may be described as a set of values, norms and attitudes people have toward searching, creating, and applying information. These values, norms and attitudes appear to shape the behaviour of an individual in the information space. Having a good information culture is crucial for professional and personal life, as well as social security. One way to form information culture is to communicate with family, friends, social communities, members of the authority, etc. This is why the term 'information culture' may be applied to every member of society having an experience with information technologies, such as the Internet.

Today, the Internet continues to grow and gain popularity as a valuable tool to enhance the traditional way of learning/teaching. It happens because it encourages and facilitates communication, gives access to an endless supply of information about everything, and helps education [2]. The advancement of information and communication technologies (ICTs) has promoted innovative forms of education and the transformation of pedagogical tools, and they were infused into a new educational paradigm [3]. For online learning to be genuinely effective, technology must facilitate communication and social processes [4].

The Internet is a novel social institution that has unique characteristics distinguishing it from the traditional ones [5]. While adhering to this opinion, this study focuses on a virtual form of social interaction supported by social network capabilities. Among other things, social networks are used for professional means. Social capital grows thanks to users, who build social connections by entering professional communities and following other users on social media. Companies use social networks to establish strong relationships with consumers, whilst consumers exploit social networks to join and follow the community of professionals, which is harder to do outside the virtual space [6].

There are reasonable grounds to believe that learning is a sociocultural process reliant on internal dialogue and motivational interaction. Yet, social networking is rarely used in education, even though it has tempting advantages, such as ease of use and availability [3].

Web 2.0 technologies are becoming an integral part of the daily lives of today's adolescents, bringing together millions of people and supporting resource sharing, information exchange, collaboration and communication [7]. The proliferation of Web 2.0 applications, especially social networking media, and the widespread use of mobile devices are helping to expand opportunities for collaborative social learning [8]. There are many different types of Web 2.0 applications, including social networking 
media (e.g., Facebook, Instagram, and Twitter), social bookmarking services (e.g., Delicious and Diigo), media sharing services (e.g., YouTube and Flickr); co-authoring tools (e.g., Wikis and blogs), and more. The functionality of Web 2.0, specifically the sharing of textual information, audio and video files, has opened a door for students to customize their learning experiences and maximize their learning outcomes. The coauthoring tools or social media such as wikis have made collaborative content creation accessible and easy to manage [9]. In addition, social networking media, including Facebook, Twitter and Instagram, have provided remarkable networking capabilities, which have allowed for nurturing and growth of an online learning community [10]. Enhanced learning systems based on social media enable learners to interact in online learning communities by creating, manipulating and sharing content, communicating and exchanging opinions. In community groups, students can collaborate, create and duplicate news, manage events, write microblogs, publish and edit wiki pages, and share resources (files, images, videos, etc.) [11]. Chat rooms, virtual communities, social networks, wikis, microblogs or video sharing sites become the centres of social lives [12]. The benefits of using Web 2.0 technologies in education are as follows: they foster involvement; they help to overcome learning and teaching challenges; they facilitate collaborative work and assessment. In addition, showing profile pictures and biographical information of users strengthens the relationship between users and creates a sense that they interact with real people. This leads to more sustained participation in training courses [13], as students receive a platform to elaborate tactics of accessible and open interaction and develop an efficient learning scenario.

This work aims to study the educational effects of Web-based tools and applications, such as microblogging platforms, social networking media, and services for sending short messages, on the process of information culture formation in an elearning setting. The objectives of the study are:

1. Building an experimental course in management psychology with Moodle by integrating Instagram as an educational tool;

2. Testing the experimental training course on a group of master-level students attending the Higher School of Economics and Business (Al-Farabi Kazakh National University) and the Institute of Economics and Management in Agribusiness (Russian State Agrarian University - Timiryazev Moscow Agricultural Academy);

3. Surveying students to find out their emotional response to the use of microblogging-based learning practices during the course;

4. Establishing the effects of microblogging practices introduced into education.

\subsection{Theoretical framework}

Social networks and mobile applications or apps have taken communication in education to a new level [14], providing technological opportunities for educators and learners to create online groups for learning purposes [15]. One tool to support participation in online learning is the Asynchronous Discussion Forum, a tool frequently embedded within institutional virtual learning environments. It is consistent with 
social constructivist approaches to learning, including collaborative learning, resource-based learning, and problem-based learning. Indeed, the activity within an online forum is considered a good indicator of the level of involvement in socioconstructivist pedagogy [16] and a reliable indicator of academic performance [17]. In addition, the use of forums aligns with cognitivism pedagogy by providing an environment to stimulate cognitive learning strategies and critical thinking [18]. Constructivism is a learner-centred approach to learning that holds that a learner constructs his or her own knowledge by connecting new information to existing knowledge or experiences [19]. However, online constructivism and argumentation practices require additional support. For this, a sociocultural activity design (SCAD) model can be used. This model supports the development of an online community of learners, where participants take over responsibility for discussions, maintain connections with peers, and engage in meaningful conversations [20].

In general, associating the possibilities of the Internet as a platform for social relationships, younger generations can quickly adapt to new forms of social interaction, such as interaction through social media, and actively engage in online projects. One may consider the impact of digital technologies on youth within the frame of ambivalent psychological and sociocultural influences. On the one hand, sharing information facilitates the development of a personality and a group, the growth in the number of socially engaged people, and the expansion of their outlook. On the other hand, any word or message may be used to manipulate others, force ideas, and control the masses. An example of this destructive content would be the idea of the isolation of the Russian Internet (Runet). In general, digital information-sharing environments become a platform to construct new values and worldviews thought to align with a new type of culture [21].

Microblogging has become increasingly popular within the education sector. The technological and functional features of microblogs allow them to be used as an educational tool for various purposes (reflective thinking, collaboration, interactivity, etc.) [22]. Microblogs provide opportunities for learners to publish their thoughts, opinions, and feelings online. They share the following features: individual ownership, posted updates displayed in reverse chronological order, and the archival of old posts [23]. Microblogs also have features that distinguish them from web pages, namely the easy creation of pages, easy filtering of content, and opportunities to invite and add other authors to the existing microblogs [24]. The microblogging tools enrich textual information with visual and audio materials and support a more flexible and open learning experience [9]. Hence, microblogging with its comment function may be considered an effective tool to increase student engagement in online activities [22].

There is a belief that microblogging is a specific form of person-group interaction, where a person who exists within cyberspace presents themselves in a certain way, translates personal values, and raises different topics to discuss on a regular basis. Those on the other side of blogs are called the subscribers, passive participants in this kind of interaction, who yet have the ability to provide feedback [25]. Bloggers are cultural carriers who potentially have the power to influence the actions of other people. From this perspective, microblogging can be considered a sociocultural process, 
as subscribers form a community of people with shared norms, values and traditions. Each social media user independently chooses a social media resource and a blogger with similar interests to follow; this choice directly depends on the extent to which the information culture of content consumers is formed. Note that this feature applies more to younger generations spending most of their time on social networks, such as Vkontakte, Instagram, etc. Among the many categories of bloggers, there are political bloggers who have millions of subscribers and tackle domestic and foreign policy issues on video hosting sites.

Due to the popularity of the Internet, new in-demand professions have emerged, such as the targeting specialist, contextual advertising specialist, web designers, internet marketer, SMM specialist, and more. Mastering one of the new professions provides opportunities for people to leverage their cultural capital, gain new social contacts, and form social capital. In this case, one may assume that representatives of these new professions share specific values and norms dedicated to handling information, goals, and models of behaviour. This indicates a high level of information culture [1].

Digitalization has many positive social and economic effects. The primary benefits include faster economic growth, development of small and medium-sized businesses, higher business efficiency, and increased employment in the information technology occupations. When it comes to society, benefits from digitalization include the growing availability of financial services, cost reduction in the education sector, improvement of health care services, and ecological footprint reduction [26].

\section{Study Design and Research Methods}

\subsection{Study design}

The Higher School of Economics and Business (Al-Farabi Kazakh National University), together with the Institute of Economics and Management in Agribusiness (Russian State Agrarian University - Timiryazev Moscow Agricultural Academy (RSAU - MTAA)), launched an experimental training course — The Psychology of Management - designed for master-level students. This course was created in Moodle and included the use of Instagram, a social networking app. The experiment lasted from February to July 2020 and involved 140 students (Table 1). 
Paper-Use of Microblogging, Social Networking, and Short Messages in E-learning for Information...

Table 1. The Psychology of Management course participants

\begin{tabular}{|c|c|c|c|}
\hline $\begin{array}{c}\text { No. of } \\
\text { students }\end{array}$ & Master's degree program & Institute/Faculty & University \\
\hline 10 & Innovational Management & \multirow{6}{*}{$\begin{array}{l}\text { Higher School of Eco- } \\
\text { nomics and Business }\end{array}$} & \multirow{6}{*}{$\begin{array}{l}\text { Al-Farabi Kazakh Nation- } \\
\text { al University }\end{array}$} \\
\hline 14 & Entrepreneurship and Law & & \\
\hline 17 & Marketing & & \\
\hline 16 & Management & & \\
\hline 15 & Project Management & & \\
\hline 9 & eCommerce & & \\
\hline 18 & Digital Technologies in Economy & \multirow{4}{*}{$\begin{array}{l}\text { Institute of Economics } \\
\text { and Management in } \\
\text { Agribusiness }\end{array}$} & \multirow{4}{*}{$\begin{array}{l}\text { Russian State Agrarian } \\
\text { University - Timiryazev } \\
\text { Moscow Agricultural } \\
\text { Academy (RSAU - } \\
\text { MTAA) }\end{array}$} \\
\hline 14 & Project Management & & \\
\hline 11 & Economics and Management & & \\
\hline 16 & $\begin{array}{l}\text { Innovational Development in Agribusi- } \\
\text { ness }\end{array}$ & & \\
\hline Total: 140 & & & \\
\hline
\end{tabular}

The Psychology of Management course for remote learning is a modular course comprising 15 modules divided into 5 thematic blocks of equal size, i.e., 3 modules per each (Fig. 1). Through the use of Moodle, students took lectures and other theoretical materials and engaged in practical works, while the autonomous creative activities were performed with the help of Instagram's features. For effective interaction among learners, 14 groups of 10 students were formed. Each group was assigned a curator who guided their way through the course. The functional responsibilities of the curator are the following: technological and informational support in performing practical assignments, consulting, progress tracking, assistance in modelling highquality content, and surveying. The autonomous creative assignments were included to help students consolidate what they have learned. Students were asked to briefly express their thoughts, attitudes, and views toward the given topic on Instagram by creating microblog posts and leave motivational and constructive comments under the microblogs of other group members. 


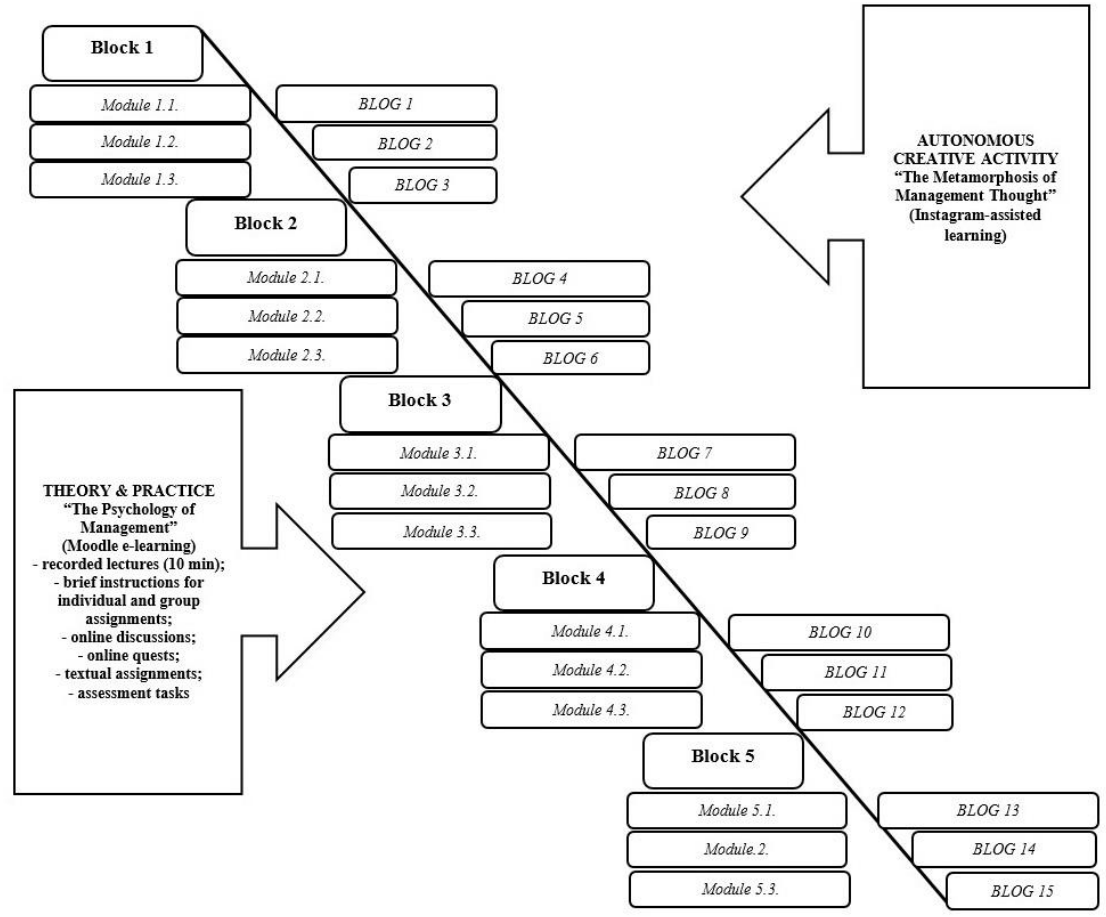

Fig. 1. The schematic representation of the experimental training course (developed by the authors)

\subsection{Research method}

This study uses empirical research methods such as questionnaire survey and observation. The survey was conducted in an online format and using the capabilities of the educational platform Moodle. Subgroup supervisors carried out the survey in two stages ( 2 months after starting the course and at the end of the course): examining emotional responses of learners and assessing the overall effect of microblogging from the student point of view. Observation of student performance in the classroom and comprehensive assessment of the survey results were carried out with the involvement of course moderators.

In this work, theoretical methods of scientific research were used, such as:

- Induction (to summarize survey results and determine educational microblogging engagement among students)

- Deduction (to assess the impact of digital technology on the organization of learning courses)

- Analysis (to establish emotional responses of learners and the effect of microblogging practice on learning)

- Synthesis (to produce conclusions about the advisability of using microblogging in the structure of online learning courses) 


\subsection{Limitations}

The limitation of this study is its descriptive design, i.e., the study presents a digest of concepts to discuss the need for innovative modes of teaching in e-learning. The results of the study can serve as a framework to quantify the effects of microblogging technology on education.

\section{Results}

Thanks to its strong emphasis on visual content, Instagram is gaining traction as one of the most aesthetic platforms to look into for a daily dose of inspiration. It becomes increasingly popular among students, who find Instagram with its friendly user interface engaging [27]. In addition to many tools and services for building an online presence, users over the past few years are enjoying technological solutions that have made online interactions more convenient and easy. The mass public appeal to social networking websites rose from the emergence of numerous mobile apps that allow posting content online via a mobile device [28].

In the context of global digital challenges, one of the primary tasks for educators is to improve the digital competence of learners. Today, digital practice such as microblogging is taking over the Internet, and the number of education bloggers is growing exponentially. Microblogging is characterized by an individual exploration of ideas of personal interest through frequent online posts, documenting ideas as they emerge over time [29]. Microblogging provides opportunities for students to study independently in a supportive social environment [30].

To establish how Instagram microblogging affects learning, curators were asked to carry out two online surveys. The first survey was conducted 2 months after starting the course to examine learners' emotional responses to the microblogging practice. The second survey was conducted at the end of the course to explore the overall effect of blogging on learning. The results from both surveys underwent a comprehensive assessment by a team of course moderators (4 teachers from the Higher School of Economics and Business and the Institute of Economics and Management in Agribusiness). The results from the first survey showed a high level of engagement in blogging. The shared feelings and emotions evoked by the microblogging practice are depicted in Fig. 2.

It is worth noting that the inspiration and enthusiasm of students seen during the experiment could stem from the fact that posting on social networks was something that students did every day and were good at. Since many participants had no habit of using Instagram for learning purposes, they presumably saw this type of activity as a new dimension of social interaction. The intellectual vector of social interaction embedded within the course expands the range of professional interests and removes barriers that hinder the presentation of personal knowledge and abilities. Many students confirmed that they had a feeling of liberation and found it easy to express their views and opinions at the end of the course. Furthermore, the opportunity to use Instagram during learning turned out to be an excellent motivational factor. 


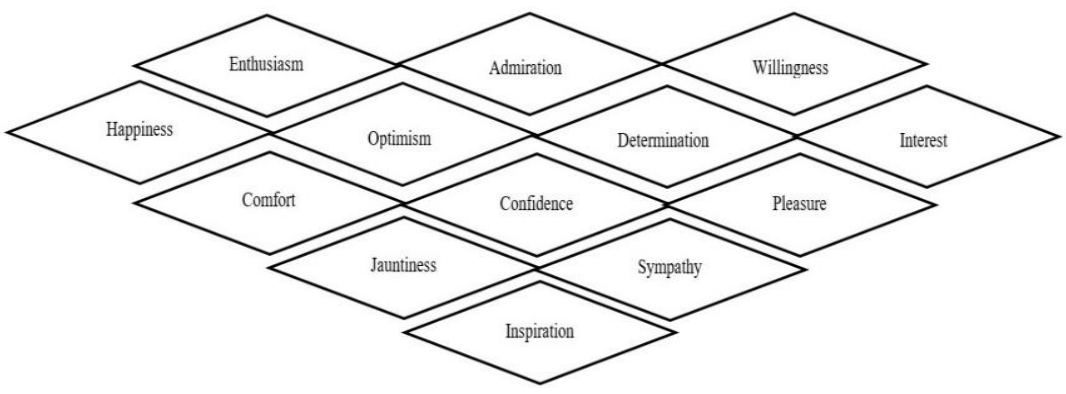

Fig. 2. A summary of students' emotional experiences after 2 months of the course (developed by the authors)

In the second survey (Fig. 3), 95\% of students have reported a positive effect of microblogging practices on their learning journey. According to $97 \%$ of students, the Instagram-assisted interaction updated the course and made it look relevant, effortless, and consistent. Eighty-nine per cent of students described the educational blog posting practice (i.e., blogging for the purpose of learning more) as a natural fit, $71 \%$ of students reported that the microblogging facilitated the formation of a collaborative learning environment and intensified their interest not only in the educational process itself but also in gaining additional knowledge. In addition, $87 \%$ of learners stated that conversations taking place in the comment section under blog posts fueled their creative self-expression and that blogs were a new way to interact within a virtual environment and build an online presence. Furthermore, $87 \%$ of respondents claimed that educational microblogging had increased the number of people they interacted with by giving them the means to build a positive relationship with other group members. Finally, $76 \%$ of students felt more competent in critical thinking and writing skills and reported better displaying professional views and thoughts. Not to mention that running an educational blog seems to have improved their skills of self-presentation on Instagram as well as the ability to attract more subscribers.

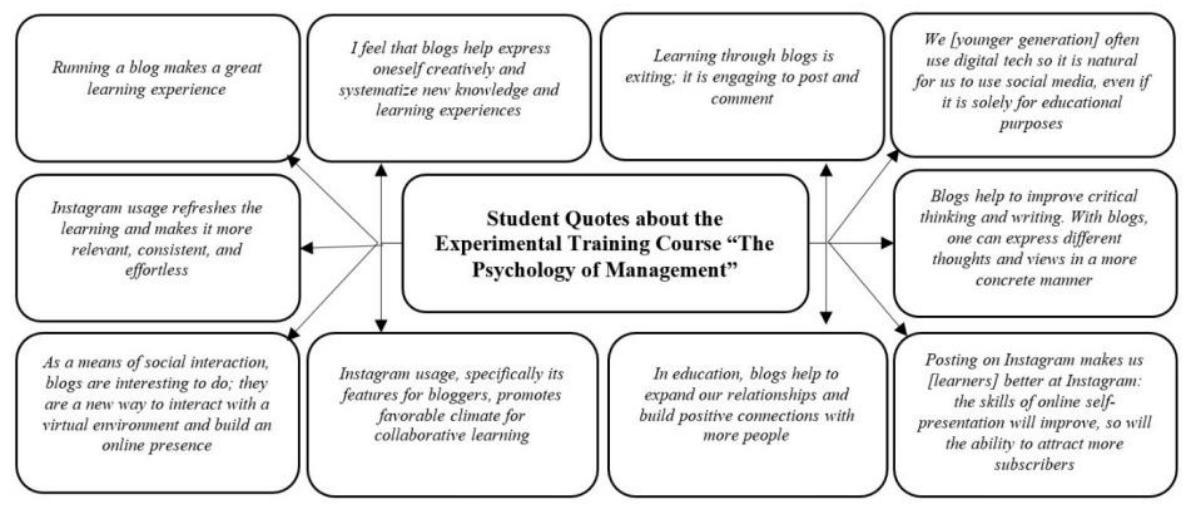

Fig. 3. Dominant opinions of educational microblogging among learners (developed by the authors) 


\section{Discussion}

The possibility of carrying out social activities using networking platforms fuels the development of communication skills. The microblogging platforms typically limit each message to a predetermined size, such that users are forced to be creative. What is more, as the number of viewers contributing to a discussion increases, the content of this particular discussion will expand. The interaction between users is a frequent exchange of messages containing viewpoints, questions, and answers. It can take different forms: one-to-one (interaction between two users); one-to-many (a single user interacts with two or more users simultaneously); and many-to-many (multiple users communicate and collaborate with each other) [31]. Participants in the present experiment hold that virtual communication with peers on Instagram improved their ability to verbally express their thoughts and construct textual content, thereby increasing their confidence in using digital communication tools. In addition, students confirmed that this practice has motivated them to self-improve, express and present themselves in a better way.

Social media becomes increasingly popular among students, as it enables communication, collaboration and exchange of information. The ease of access and ease of use make social media a very effective tool for exchanging ideas. Using Instagram allows students to generate contextually relevant ideas and fain an engaging learning experience [32]. Instagram can be an excellent educational tool that makes the learning process unique, engaging, and meaningful [33]. In addition, Instagram as a tool allows guiding the learning process towards a more constructivist paradigm where students are actively involved in the process of knowledge construction, instead of passively receiving information, which entails a better mastery of the course material. By encouraging students to interact with each other and with the content of the course, microblogging helps to transform information into knowledge [34]. In addition, the constant flow of information between students and the teacher supports the iterative process of knowledge creation [35].

Due to its mobility, Instagram enables students and teachers to interact synchronously or asynchronously, stay connected, and access knowledge easily and comfortably [36]. The rapid feedback gathered on social media effectively supports a processoriented approach to learning. By fostering interaction, social media encourage students to communicate, collaborate, participate and learn. Using social media tools properly can positively affect the primary outcomes of learning, such as knowledge, skills and attitudes [13].

Integrating Instagram in education stimulates students to actualize their abilities, expand the sphere of professional hobbies and interests, and be creative. Today, social media-assisted and project-based learning may contribute to a better understanding of learning materials and offer enhanced opportunities for learners to apply their newly acquired knowledge and skills in real-life social contexts.

The integration of social media in higher education has a significant impact on learning and teaching. Yet, they also become an arena of contestation over teaching and learning technologies. Social media are a critical feature of contemporary communication, encompassing a wide range of virtual tools and platforms that increase 
and enhance the sharing of information. This new form of media makes the transfer of text, photos, audio, video, and news increasingly fluid among Internet users [37]. Social platforms can provide students with a broader space to learn and communicate. With its advantages of rapid updating of information and high communication speed, microblogging is very popular among students and plays a crucial role in the formation of their professional views and personal values [38].

Social media usage among teachers can have different benefits, ranging from a better understanding of the material by learners to enhanced interaction with colleagues and lecturers [39]. Scientists currently focus on exploring these benefits and identifying ways to incorporate social media into different learning scenarios. The common findings can be described as follows:

- The main factors for social media usage in higher education are perceived ease of use, subjective norm, and perceived playfulness. [40]

- Social networks are indeed a powerful tool to instill thinking and writing skills in students, as well as foster a positive interpersonal attitude among them. [41]

- Besides the stimulating function, the use of social media to carry out teaching with university students promotes a pleasant and motivating learning climate [3].

- Learning communities on social media are divided into three categories: communities of practice (CoP), professional learning communities (PLC), and professional learning networks (PLN). A successful learning network or community enhances communication, collaboration and support among members by providing equal access to information [42].

- If appropriately deployed, social media can facilitate a learner-centred approach to learning and enhance the sharing of information 24/7 [43].

- The use of a microblogging platform (such as Twitter) can improve the learning outcomes, especially if it is a 'push' technology and a platform for peer interaction [44].

- The use of social networks in higher education is largely initiated by students who actively use social media for communication [45].

- Microblogging on social media has a positive effect on the processes of socialization, externalization, combination and internalization [46,47].

- Microblogging services, popular tools to build social presence and reputation on the Internet [28], contribute to the dissemination of knowledge [48].

- In corporate training, microblogging services are used to facilitates task coordination, task delegation, coordination of meetings, and sharing of ideas [49].

- Microblogs may be used to distribute links to educational resources, related articles, curriculum materials, and lesson plans [50].

- Microblogging technology has a great potential for motivating e-learning participants [51].

Since the number of information flows continues to grow, the role of information culture will increase too. One should keep in mind that without strong social ties, social capital could not be constructed. Therefore, having a good information culture is vital, as it helps build strong social connections in the virtual environment and gain professional competitiveness. 


\section{Conclusion}

The study made it possible to assess the impact of innovative teaching methods (the use of microblogging, social networks and services for sending short messages) on the formation of information culture in an online learning setting. The creation of an experimental course in management psychology and its testing among students of the Higher School of Economics and Business (Al-Farabi Kazakh National University) and the Institute of Economics and Management in Agribusiness (Russian State Agrarian University - Timiryazev Moscow Agricultural Academy) made it possible to assess the educational effects produced by microblogging-based learning practices during the course.

This study presents subjective feedback on the effect of Instagram usage on the learning journey of master-level students taking the experimental course - The Psychology of Management. The majority of respondents confirmed the positive impact of running microblogs (95\%), reported the improvement of the learning assignments in terms of consistency, complexity, and relevance (97\%), as well as the enhancement of the learning climate $(71 \%)$, critical thinking and writing skills $(76 \%)$, learning motivation $(71 \%)$, and skills necessary for social presence building $(76 \%)$. The bulk of students also described blogs as a natural fit for contemporary learners (89\%) and a tool fostering interaction between students for the purpose of learning more (87\%).

Based on the above, the following conclusions were made. First, the competent use of Internet technologies provides opportunities for knowledge seekers to self-improve, which, in turn, contributes to the formation of the information culture. Secondly, by enhancing information culture, a person acquires either personal or professional competencies, or both, and thus generates social capital. Third, younger generations are better at adapting to new forms of social interaction. Meanwhile, a high level of engagement facilitates the formation of social capital on social media. Fourth, microblogging is a specific form of person-group interaction that contributes to social capital formation. Bloggers exhibit a high level of information culture, which gives them the ability to unite their subscribers with similar views and interests.

\section{References}

[1] Berman, N.D. (2017). Information culture as the basis of professional activity. Modern Studies of Social Issues, 8(6-2): 354-357.

[2] Gernsbacher, M.A. (2015). Why internet-based education? Frontiers in Psychology, 5(1530): 1-4.

[3] Ricoy, M.C., Feliz, T. (2016). Twitter as a learning community in higher education. Educational Technology \& Society, 19(1): 237-248.

[4] Dunlap, J.C., Lowenthal, P.R. (2009). Tweeting the night away: Using Twitter to enhance social presence. Journal of Information Systems Education, 20(2): 129-135.

[5] Ugolkov, N.V. (2012). Internet as an institution of socialization of senior schoolchildren: the abstract of $\mathrm{PhD}$ thesis in Pedagogy. Moscow: Moscow State Pedagogical University.

[6] Nim, E.G., Skvortsova, D.A. (2017). The development of social capital in the context of professional networks and communities mediatization. RUDN Journal of Studies in Litera- 
ture and Journalism, 22(3): 509-520. https://doi.org/10.22363/2312-9220-2017-22-3-509$\underline{520}$

[7] Alamri, M.M., Almaiah, M.A., Al-Rahmi, W.M. (2020). Social media applications affecting students' academic performance: A model developed for sustainability in higher education. Sustainability, 12(16): 6471. https://doi.org/10.3390/su12166471

[8] Hsu, Y.C., Ching, Y.H. (2012). Mobile microblogging: Using Twitter and mobile devices in an online course to promote learning in authentic contexts. International Review of Research in Open and Distributed Learning, 13(4): 211-227. https://doi.org/10.19173/irrod 1.v13i4.1222

[9] Luo, T., Franklin, T. (2015). Tweeting and blogging: Moving towards education 2.0. International Journal on E-Learning, 14(2): 235-258.

[10] Lu, W. (2010). How social network position relates to knowledge building in online learning communities? Integrated education and technology, 5(1): 4-25.

[11] Silius, K., Kailanto, M., Tervakari, A.M. (2011). Evaluating the quality of social media in an educational context. International journal of Emerging Technologies in Learning, 6(3): 21-27. https://doi.org/10.3991/ijet.v6i3.1732

[12] Direktor, C., Nuri, C., Okray, Z., HuseyinzadeSimsek, A. (2019). The relationship between social sharing sites users' personality beliefs and purposes of using social sharing sites of university students. Cypriot Journal of Educational Sciences, 14(2): 313-321 . https://doi.org/10.18844/cjes.v14i2.4132

[13] Korucu, A.T., Atun, H. (2017). Use of social media in online learning. In Handbook of Research on Innovative Pedagogies and Technologies for Online Learning in Higher Education. IGI Global, pp. 1-18. https://doi.org/10.4018/978-1-5225-1851-8.ch001

[14] Denizalp, H., Ozdamli, F. (2019). Determination of student opinions on usage of social media and mobile tools in student-teacher, student-student communication. International journal of Emerging Technologies in Learning, 14(22): 19-28. https://doi.org/10.3991/ij et.v14i22.11745

[15] Imlawi, J., Gregg, D., Karimi, J. (2015). Computers \& education student engagement in course-based social networks: The impact of instructor credibility and use of communication. Computers \& Education, 88: 84-96. https://doi.org/10.1016/j.compedu.2015.04.015

[16] Macfadyen, L.P., Dawson, S. (2010). Mining LMS data to develop a Bearly warning system for educators: A proof of concept. Computers \& Education, 54(2): 588-599. https://doi.org/10.1016/j.compedu.2009.09.008

[17] Dawson, S. (2010). 'Seeing' the learning community: An exploration of the development of a resource for monitoring online student networking. British Journal of Educational Technology, 41(5): 736-752. https://doi.org/10.1111/j.1467-8535.2009.00970.x

[18] Dommett, E.J. (2019). Understanding student use of twitter and online forums in higher education. Education and Information Technologies, 24(1): 325-343. https://doi.org/10.10 $\underline{07 / \mathrm{s} 10639-018-9776-5}$

[19] Henson, K.T. (2003). Foundations for learner-centred educational: A knowledge base. Computers \& Education, 124(1): 5-16.

[20] Borge, M., Ong, Y.S., Goggins, S. (2020). A sociocultural approach to using social networking sites as learning tools. Educational Technology Research and Development, 68(3): 1089-1120. https://doi.org/10.1007/s11423-019-09721-z

[21] Zubok, Y.A., Chuprov, V.I. (2019). The activity of youth in the cultural space of changing reality: theoretical approaches to research. In The Cultural Space of Youth: Meanings and Practices. Proceedings of the All-Russian Scientific and Practical Conference. PERSPECTIVA Publishers, Moscow. 
[22] Kilic, E., Gokdas, I. (2014). Learning through blogging: Use of blogs to enhance the perceived learning of pre-service ICT teachers. Educational Sciences: Theory \& Practice, 14(3): 1169-1177. https://doi.org/10.12738/estp.2014.3.1987

[23] Sim, J.W.S., Hew, K.F. (2010). The use of weblogs in higher education settings: A review of empirical research. Educational Research Review, 5(2): 151-163. https://doi.org/10.10 16/j.edurev.2010.01.001

[24] Nedeva, V., Nedev, D. (2010). A new approach of e-learning education using blogging. Journal "Scientific Bulletin", Petroleum-Gas University of Ploiesti, 62(1B): 162-169.

[25] Kolmykova, M.A. (2019). Blogging as a sphere of youth socialization. In Higher Education in the XXI century: The Role of Humanities Education in the Context of Technological and Socio-Cultural Changes. Proceedings of the XV International Scientific Conference (November 14-16, 2019, Moscow). Part I. Moscow University for the Humanities, pp. 428-432.

[26] Tovma, N., Ussabayev, A., Baimukasheva, Z., Tyurina, Y. (2020). Marketing ensuring of the competitiveness of the Republic of Kazakhstan regions in the transition to the digital economy. Management Science Letters, 10(7): 1575-1586. https://doi.org/10.5267/j.msl. 2019.12.009

[27] Atamaniuk, M. (2019). How Instagram Can Contribute to eLearning in 2019. https://elear ningindustry.com/instagram-can-\%D1\%81ontribute-to-elearning-2019

[28] Kieslinger, B., Ebner, M., Wiesenhofer, H. (2011). Microblogging practices of scientists in e-learning: A qualitative approach. International Journal of Emerging Technologies in Learning, 6(4): 31-39. https://doi.org/10.3991/ijet.v6i4.1820

[29] Relojo, D. (2017). Blog psychology: Insights, benefits, and research agenda on blogs as a dynamic medium to promote the discipline of psychology and allied fields. Psychreg Journal of Psychology, 1(2): 70-75.

[30] Boltivets, S., Acharya, S., Santos, A. (2018). Educational blogging: Implications, benefits and challenges to pedagogical practice. Psychreg Journal of Psychology, 2(2): 105-114.

[31] Cleveland, S., Ellis, T., Hinojosa, C. (2015). Knowledge exchange via unified communication services: A grounded theory approach. In 21st Americas Conference on Information Systems, Puerto Rico, 13-15 August 2015. Association for Information Systems.

[32] Handayani, F. (2019). Instagram as a teaching tool? Really? In Igniting a Brighter Future of EFL Teaching and Learning in Multilingual Societies, Fourth International Seminar on English Language and Teaching (ISELT-4). Padang: Universitas Negeri Padang, pp. 320327. https://doi.org/10.2991/iselt-17.2017.41

[33] Kirst, M.W. (2016). Instagram as an Educational Tool for College Students. http://colleg epuzzle.stanford.edu/?p=5057

[34] Prestridge, S. (2014). A focus on students' use of Twitter - Their interactions with each other, content and interface. Active Learning in Higher Education, 15: 101-115. https://doi.org/10.1177/1469787414527394

[35] Ebner, M., Lienhardt, C., Rohs, M., Meyer, I. (2010). Microblogs in higher education - A chance to facilitate information and process-oriented learning? Computers \& Education, 55: 92-100. https://doi.org/10.1016/j.compedu.2009.12.006

[36] Veletsianos, G., Kimmons, R., French, K. (2013). Instructor experiences with a social networking site in a higher education setting: Expectations, frustrations, appropriations, and compartmentalization. Education Technology Research and Development, 61: 255-278. https://doi.org/10.1007/s11423-012-9284-Z

[37] Willems, J., Adachi, C., Bussey, F., Doherty, I., Huijser, H. (2018). Debating the use of social media in higher education in Australasia: Where are we now? Australasian Journal of Educational Technology, 34(5): 135-149. https://doi.org/10.14742/ajet.3843 
[38] Yang, P., Li, W. (2019). Behavior analysis of college students on using microblog in big data environment. In IOP Conference Series: Materials Science and Engineering. IOP Publishing, Vol. 569, No. 5, p. 052098. https://doi.org/10.1088/1757-899x/569/5/052098

[39] Alalwan, N., Al-Rahmi, W.M., Alfarraj, O., Alzahrani, A., Yahaya, N., Al-Rahmi, A. M. (2019). Integrated three theories to develop a model of factors affecting students' academic performance in higher education. IEEE Access, 7: 98725-98742. https://doi.org/10.1109/ access.2019.2928142

[40] Dumpit, D.Z., Fernandez, C.J. (2017). Analysis of the use of social media in Higher Education Institutions (HEIs) using the Technology Acceptance Model. International Journal of Educational Technology in Higher Education, 14(1): 5. https://doi.org/10.1186/s41239$\underline{017-0045-2}$

[41] Jamari, D., Abdullah, Z., Mohamed, H., Zaid, N.M., Aris, B. (2017). Social media in learning: insights of high schools. Advanced Science Letters, 23(8): 7477-7481. https://doi.org/ 10.1166/asl.2017.9502

[42] Robinson, H., Kilgore, W., Bozkurt, A. (2020). Learning communities: Theory and practice of leveraging social media for learning. In G. Durak, \& S. Çankaya (Eds.), Managing and Designing Online Courses in Ubiquitous Learning Environments. Hershey, PA: IGI Global, pp. 72 91. https://doi.org/10.4018/978-1-5225-9779-7.ch004

[43] Chawinga, W.D. (2017). Taking social media to a university classroom: teaching and learning using Twitter and blogs. International Journal of Educational Technology in Higher Education, 14(1): 3. https://doi.org/10.1186/s41239-017-0041-6

[44] Tang, Y., Hew, K.F. (2017). Using Twitter for Education: Beneficial or simply a waste of time? Computers and Education, 106: 97-118. https://doi.org/10.1016/j.compedu.2016.1 $\underline{2.004}$

[45] Aleksandrova, Y.G., Parusheva, S.S. (2019). Social media usage patterns in higher education institutions-an empirical study. International Journal of Emerging Technologies in Learning, 14(5): 108-121. https://doi.org/10.3991/ijet.v14i05.9720

[46] Cleveland, S., Jackson, B.C., Dawson, M. (2016). Microblogging in higher education: Digital Natives, knowledge creation, social engineering, and intelligence analysis of educational tweets. E-learning and Digital Media, 13(1-2): 62-80. https://doi.org/10.1177/2042 753016672130

[47] Collins, R., Deek, F., Hiltz, S. (2015). Share and Share Alike: Integrating Internet Resource Sharing into Learning. In $21^{\text {st }}$ Americas Conference on Information Systems. Association for Information Systems, Puerto Rico.

[48] Seebach, C. (2012). Searching for answers-knowledge exchange through social media in organizations. In 45th Hawaii International Conference on System Science (HICSS), 4-7 January 2006. Maui, HI: IEEE, pp. 3908-3917. https://doi.org/10.1109/hicss.2012.514

[49] Riemer, K., Altenhofen, A., Richter, A. (2011). What are you doing? -Enterprise microblogging as context building. In $19^{\text {th }}$ European Conference on Information Systems, 911 June 2011. Helsinki, Finland: AIS.

[50] Carpenter, J.P. (2014). Twitter's capacity to support collaborative learning. International Journal of Social Media and Interactive Learning Environments, 2(2): 103-118. https://doi.org/10.1504/ijsmile.2014.063384

[51] Pauschenwein, J., Sfiri, A. (2010). Adult Learner`s Motivation for the Use of Microblogging during Online Training Courses. International Journal of Emerging Technologies in Learning, 5(1): 22-25. https://doi.org/10.3991/ijet.v5i1.1041 


\section{Authors}

Marina Kolmykova is a PhD of Sociological Sciences, Associate Professor of the Department of State and Municipal Administration, Orenburg State University, Orenburg, Russian Federation. mari_kol@mail.ru

Nadezhda Gavrilovskaya is a $\mathrm{PhD}$ of Engineering Sciences, Associate Professor of the Department of Information Technology in the Agro-Industrial Complex, Russian State Agrarian University - Moscow Timiryazev Agricultural Academy, Moscow, Russian Federation.

Mariya Barsukova is a Senior Lecturer of the Department of General and Engineering Ecology, Russian State Agrarian University - Moscow Timiryazev Agricultural Academy, Moscow, Russian Federation.

Daria Kozlovskaya is a Bachelor of the Department of Social Work, Russian State Social University, Moscow, Russian Federation

Article submitted 2021-03-02. Resubmitted 2021-05-26. Final acceptance 2021-05-26. Final version published as submitted by the authors. 